\title{
The types of infinitive constructions with predicatives (according to the Russian National Corpus)
}

\author{
Kustova G. I. \\ Vinogradov Russian Language Institute \\ of the Russian Academy of Sciences; \\ Moscow, Russia \\ galinak03@gmail.com
}

\begin{abstract}
The paper considers constructions «predicative + infinitive». For the first time, a class of interpretive infinitive constructions (opposed to emotional reactions) is introduced. For emotional reactions, the predicative and the infinitive refer to the same subject, the infinitives of the perception, mental, speech verbs are typical for them: It hurts / scares to see how forests are dying ('X sees, $\mathrm{X}$ is scared') $\rightarrow$ It hurts that forests are dying. For interpretive constructions, the subjects of the predicative and the infinitive do not coincide: It is heartless to separate the mother from the children - ' $\mathrm{X}$ separates, $\mathrm{Y}$ evaluates such an act as heartless'. The infinitives of perceptual and mental verbs in such a construction are either not used, or they denote a kind of action: It is tactless to listen to private conversations.
\end{abstract}

Keywords: predicate; infinitive construction; interpretation predicates

DOI: $10.28995 / 2075-7182-2021-20-456-463$

\section{Типы инфинитивных конструкций с предикативами (по данным Национального корпуса русского языка)}

\author{
Кустова Г. И. \\ Институт русского языка \\ им. В. В. Виноградова РАН; \\ Москва, Россия \\ galinak03@gmail.com
}

\begin{abstract}
Аннотация
В работе рассматриваются конструкции «предикатив + инфинитив». Впервые вводится класс интерпретационных инфинитивных конструкций, которые противопоставляются эмоциональным реакциям. У эмоциональных реакций предикатив и инфинитив относятся к одному и тому же субъекту, для них типичны инфинитивы глаголов восприятия, ментальные, речевые: Больно / страшно видеть, как гибнут леса ('X видит, $\mathrm{X}$-у больно / страшно') $\rightarrow$ Больно, что гибнут леса. У интерпретационных конструкций субъекты предикатива и инфинитива не совпадают: Бессердечно разлучать мать с детьми - Х разлучает, Ү оценивает такой поступок как бессердечный. Инфинитивы перцептивных и ментальных глаголов в такой конструкции либо не употребляются, либо обозначают своего рода поступок: Бестактно слушать частные разговоры.

Ключевые слова: предикатив; инфинитивная конструкция; предикаты интерпретации
\end{abstract}

\section{1 Введение}

С предикативом, или категорией состояния, cp. [Shcherba 1974 / 2004], связано множество проблем, которые мы здесь не можем рассматривать, - например, является ли предикатив особой частью речи, как он соотносится с кратким прилагательным и наречием, какие подлежащные свойства имеет дативный субъект предикатива и т.п., ср. [Letuchii 2018], [Sigurðsson 2002]. 
Предметом рассмотрения в данной работе являются только инфинитивные конструкции с предикативом: Praed + Inf (рус. вариант обозначения: ПИнф).

Мы исходим из фундаментального постулата Московской семантической школы ([Apresjan 1974; 2006a]; [Paducheva 2004]), который выдвигали и другие исследователи и научные школы ([Wierzbicka 1985; 1988]): валентности (как и другие свойства языковой единицы) в общем случае определяются ее семантической структурой (при этом способы выражения (заполнения) валентностей, что важно для нашей темы (см. раздел 2), могут быть неканоническими, cp. [Boguslavskij 1996]). Если предикативы, обозначающие простейшие физиологические состояния и реакции, имеют только субъекта (это лицо, ср. Детям холодно, или окружающая среда, ср. На улице холодно), то предикативы более высокого ранга - эмоциональные реакции, восприятие, ментальные состояния, модальные предикативы - имеют еще одну валентность - пропозициональную, выражаемую инфинитивом (Трудно решить эту задачу) или зависимой клаузой (Сльшно, как дождь стучит по крыше; Приятно, что вы не забыли о нашей просьбе; Нужно, чтобы все пришли вовремя). Иногда такая валентность обозначается единым термином «сентенциальный актант» [Letuchii 2018]. Мы будем различать на синтаксическом уровне сентенциальный актант (придаточное предложение) и зависимый инфинитив. На уровне семантической структуры, как будет показано ниже, инфинитивы имеют разный статус.

В русском языке есть разные модели сочетания главного предиката и зависимого инфинитива. Обычно они рассматриваются на материале глаголов. Для глагольных конструкций принято различать три разных статуса подчиненного инфинитива - субъектный, объектный и целевой (пошел купить хлеба). Нас интересуют две первые модели:

субъектный инфинитив - оба действия (и оба глагола) относятся к одному субъекту; формула - ХХ: продолжсл (X) разговаривать (X), удалось (X) отправить (X) телеграмму: Х-у удалось, $\mathrm{X}$ отправил. Назовем такую конструкцию моносубъъектной;

объектный инфинитив: контролер (Y) и исполнитель (Х). Формула -YХ: Командир приказал солдатам стрелять: Y приказал, Х должен стрелять (конструкция ҮХ обычно может быть преобразована в придаточное: приказал, чтобы стреляли); Родители запретили мальчику выходить из дома: Y запретил, X не должен выходить. Назовем такую конструкцию разносубъектной (разумеется, есть случаи кореферентности Ү и X: приказал / запретил себе, где $\mathrm{Y}=\mathrm{X}$ ).

Конструкции ПИнф с точки зрения соотношения субъектов обычно не рассматриваются. Между тем у сочетаний ПИнф могут быть те же два соотношения субъектов предикатива и зависимого инфинитива - моносубъектное $(\mathrm{XX})$ и разносубъектное $(\mathrm{YX}),-$ что и у сочетаний глаголов.

Соотношение субъектов в конструкции ПИнф зависит от семантики предикатива. В литературе выделяются разные семантические классы предикативов - оценки (разных типов), ощущения, эмоции, ментальные, модальные, уместность, релевантность, эффективность, параметризуемый признак, свойства места и др., ср. [Letuchii 2018], [Serdobol'skaya, Toldova 2014], [Zimmerling $2017,2018]$. Однако нас эти классы интересуют не сами по себе, а относительно инфинитивной конструкции. Поэтому мы сразу исключаем перцептивные (видно, сльшно, как $P$ ) и ментальные ( понятно, ясно, очевидно, известно, что $P$ ) предикативы, которые не сочетаются с инфинитивом (*сльшно стучать по крыше 'слышен стук'; *понятно читать 'понятен текст').

С точки зрения инфинитивной конструкции предикативы можно свести к двум большим классам:

внутренние оценки, или эмоциональные реакции, - моносубъектные конструкции;

внешние оценки, или интерпретации, - разносубъектные конструкции.

Нас будут интересовать, в первую очередь, интерпретации, которые как особая группа до сих пор специально не описывались. Но рассматривать интерпретации мы будем на фоне и в сопоставлении с другим, более освоенным в лингвистических исследованиях классом - эмоциями (внутренними оценками). В работе [Serdobol'skaya, Toldova 2014] вводится противопоставление эмоциональной оценки (Людям интересно работать в консалтинге), где обычно выражается субъект эмоционального состояния, и собственно оценки, где может выражаться субъект оценки (Для меня это недорого, с. 445) или другой участник - ориентир (собственно оценочный предикатив описывает ситуацию извне, «с объективных позиций» (с. 468), ср.: Неделя началась неудачно для доллара и удачно для акций). Как видно из примеров, в работе [Serdobol'skaya, Toldova 2014] рассматриваются не только предикативы (в строгом смысле - сказуемые безличных 
предложений), но и наречия (хотя все единицы при этом называются предикативами). И субъект, и ориентир в таких конструкциях могут выражаться дативом или предложной группой для Род. В приводимой ниже классификации используются несколько иные критерии противопоставления, хотя мы тоже выделяем группу эмоциональных оценок.

\section{2 Внутренние оценки = эмоциональные реакции}

The Ядро класса внутренних оценок, т.е. моносубъектного класса, составляют предикативы эмоциональной реакции. Эмоциональные предикативы (страшно, стылдно, радостно, грустно, обидно, досадно, приятно, неприятно и под.), как и хорошо описанные в литературе эмоциональные глаголы (ср. радоваться, огорчаться и под., ср. [Apresjan 1974], [Paducheva 2004], [Zaliznyak 2006]), обозначают комплексную психологическую ситуацию, которая включает три базовых компонента, характерных для эмоциональных реакций:

(a) Ситуация Р - причина-содержание, является каузатором, вызывающим эмоциональную реакцию

(б) Оценка ситуации $\mathrm{P}$ - положительная или отрицательная

(в) Переживание - положительное или отрицательное ('приятно' vs. 'неприятно').

Переживание, т.е. состояние, само по себе не имеет валентности на ситуацию (состояние одноместно - оно имеет только субъекта), а оценка имеет пропозициональный объект Р (пропозициональное содержание). В результате совмещения образуется гибридный предикат с пропозициональным актантом Р. Р может выражаться не только клаузой (ср.: Мне очень больно, что все так получается [Дмитрий Емец. Таня Гроттер и магический контрабас (2002)]), но и инфинитивом, ср.: Вознесенскому было тяжело и больно жить [Марина Зайонц. Если бы знать... (19902000)]. Кроме собственно эмоциональных оценок выделяется еще группа ментальных оценок удивительно, интересно, странно, смешно, забавно.

В конструкции ПИнф происходит генерализация семантики предикативов и формируются два больших класса оценок - положительных ('приятно') и отрицательных ('неприятно'). В результате процесса генерализации эмоциональные реакции пополняются предикативами из других семантических классов. Так, физиологические состояния-реакции могут «повышаться» до психологических реакций (с соответствующим изменением значения). Дальше всего на этом пути продвинулись больно, горько и тяжело (Мне больно / горько, что я тебя обидел; Тяжело расставаться с друзьями). В меньшей степени этим процессом затронуты сладко и вкусно (Было удобно сидеть, было вкусно пить чай с мёдом [Фридрих Горенштейн. Куча (1982)]; Тома поняла, что ей вкуснее смотреть, как ест ребёнок, чем есть самой... [Людмила Улицкая. Казус Кукоцкого, 2000]; Мне очень сладко, что изнаночной канвой рассказа явилась самурайская книга «Хагакурэ» [Интернет-альманах «Лебедь», 2003.09.28] ₹ 'приятно').

В инфинитивной конструкции с предикативами внутренней оценки семантически противопоставлены два класса инфинитивов: (1) инфинитивы перцептивных, ментальных и речевых глаголов, обозначающие «внутренние», информационные процессы в сознании человека (видеть, воображать, сказать и под.), которые мы будем называть информационными глаголами, и (2) инфинитивы «обычных», не-информационных глаголов.

\section{1 Инфинитивы информационных глаголов.}

С семантической точки зрения инфинитив не входит в сферу действия эмоционального предикатива: страшно смотреть не означает, что человеку страшно находиться с открытыми глазами, страшно сказать не значит, что страх вызывает само произнесение слов. Речь идет о другом причиной и содержанием эмоциональной реакции, переживания является ситуация Р, которая зависит от информационного глагола $\mathrm{V}:$ Страшно смотреть $[\mathrm{V}]$, как гибнут леса $[\mathrm{P}] \approx$ Страшно, что гибнут леса $[\mathrm{P}]$ (Р = 'гибнут леса').

Субъект предикатива и инфинитива один и тот же (XX). Инфинитив V обозначает тот информационный канал, по которому поступает информация о Р. Таким образом, синтаксически зависимый от предикатива инфинитив не заполняет семантическую валентность предикатива, но вводит ситуацию (пропозицию) Р, которая, будучи валентностью инфинитива, семантически заполняет также валентность эмоционального предикатива (инфинитив может присоединять не только 
клаузу, но и, например, номинализацию, ср.: Мне больно чувствовать вашу подавленность $и$ вашу скорбь! [Борис Васильев. Вещий Олег (1996)]).

Данный семантико-синтаксический казус напоминает случай, который хорошо описан для предметных актантов - так называемое расщепление валентности: Погладил голову ребенка - погладил ребенка по голове (см. [Apresjan 1974: 153-155]. У головы как части тела есть валентность на целое (ребенок), но в предложении происходит переподчинение, и этот элемент высказывания (ребенок) приобретает связь с глаголом. Другая, еще более близкая аналогия экспликации канала восприятия - конструкции типа видел своими глазами. Глаза - это орган, который отвечает за восприятие, через который поступает информация из мира (здесь экспликация неотличима от дублирования).

В конструкции ПИнф ситуация Р расщепляется на собственно содержание и канал восприятия. Инфинитивы смотреть, слушать, видеть, сльлиать - канал, по которому информация Р поступает из внешнего мира; думать/подумать, вспомнить/вспоминать, представить, вообразить канал, через который информация Р поступает в активное поле сознания из памяти или актуально создается субъектом. Страшно сказать значит примерно то же: в сознании актуализировалась ситуация Р, о которой субъект сообщает. Актуализация ситуации Р сопровождается переживанием. В синтаксическом смысле здесь наблюдается процесс, обратный процессу расщепления предметной валентности: если там чужая, «дальняя» валентность приближалась к предикату, непосредственно подчинялась ему, то здесь своя валентность Р «отодвигается», «отдаляется» от эмоционального предикатива, и между ними возникает «мостик», прокладка в виде информационного глагола: Страшно ('плохо'), что гибнут леса $\rightarrow$ Страшно смотреть, как гибнут леса. При включении информационного инфинитива усиливается эмоциональная составляющая предикатива: из «очищенной» оценки ('плохо’) он превращается (возвращается обратно) в эмоциональное переживание: 'когда X воспринимает ситуацию Р, X испытывает отрицательные эмоции'.

Заметим (это важно для сравнения с предикативами второй группы - интерпретациями), что глаголы активного восприятия (cлушать, смотреть) и пассивного восприятия (cльлшать, виdemb) в эмоциональной группе практически нейтрализуются и значат одно и то же - поступление информации о ситуации Р, ср.: страшно / неприятно / противно / приятно смотреть, как $P \approx$ страшно / неприятно / противно / приятно видеть, как $P$ / что $P$ (какие-то семантические различия, конечно, сохраняются, однако это отдельная тема, в которую мы не можем углубляться).

У некоторых предикативов данной группы (ср. завидно) все зависимые инфинитивы, по данным НКРЯ, - информационные (завидно видеть, глядеть, представить, слушать, смотреть).

\section{2 Инфинитивы не-информационных глаголов.}

Второй вариант инфинитива - не-информационные глаголы.

Среди конструкций с не-информационными инфинитивами встречаются случаи, когда инфинитив входит в семантическую сферу действия предикатива, т.е. когда эмоция распространяется на саму ситуацию V (V = P): Обидно проиграть / упустить ипиона ('обидно, что проиграл / упустил шпиона'), - но такие случаи единичны.

В большинстве случаев не-информационный инфинитив V не входит в семантическую сферу действия предикатива, не заполняет его пропозициональную валентность, а служит (подобно информационному инфинитиву) «прокладкой», «связкой», переходным звеном к ситуации Р, которая и является сферой действия предикатива. Таким образом, конструкция оказывается смещенной, но, в отличие от случаев типа Страшно видеть, что $P$, где Р эксплицитно выражается, слушающий должен сам реконструировать ситуацию Р, которая вызывает реакцию: Мальчику было страшно ходить ночью через весь коридор в туалет [«Столица», 1997.08.26] - ходить не входит в семантическую сферу действия страшно, т.к. здесь нет смысла 'страшит, пугает ходьба'; мальчика страшит, пугает темнота ('ночью') и связанные с нею опасности; Олегу было страшно нажсимать кнопку звонка. Если дети решительно и однозначно настроень против него, он не представлял, как это переживет [Виктор Мясников. Водка (2000)] - страх вызывает не нажатие кнопки звонка, а то, что за ним последует, - будущая встреча (возможно, неудачная). 


\section{3 Внешние оценки $=$ интерпретации}

Схема внешней оценки, как уже говорилось, - YX: Hy, да это ваме дело, хоть и неосмотрительно портить здоровье [К. М. Станюкович. Жрецы (1897)] - инфинитив здесь обозначает ситуацию V с субъектом X ('X портит здоровье'), предикатив неосмотрительно обозначает внешнюю оценку субъекта-интерпретатора $\mathrm{Y}$, который не участвует в ситуации $\mathrm{V}$, а оценивает ее со стороны ('Y считает поведение X-a неосмотрительным, предосудительным, не одобряет его'). Разумеется, поскольку оценка направлена на $\mathrm{X}$-а, его поведение или поступки, она связана не только с Y-ом, но и с X-ом тоже. Однако такая ситуация всегда возникает в разносубъектных конструкциях: в случае Командир приказал солдатам стрелять приказ Y-a тоже направлен на $\mathrm{X}$ a (связан с X-ом); важно, что сам Y в ситуации инфинитива не участвует.

Внешние оценки по-другому можно назвать интерпретациями. В работе [Apresjan 2006b] описаны семантические различия глагольных предикатов оценки и интерпретации. Однако проекция этой глагольной классификации на предикативы - тема отдельного большого исследования. Пока ограничимся следующими замечаниями. Суть внешней оценки (интерпретации) заключается в позиции интерпретатора: он смотрит на ситуацию не просто со стороны, как внешний наблюдатель, а, так сказать, с более высокой позиции - с позиции превосходства. Это очевидно в случаях осуждения X-a: Безответственно / бессовестно / нечистоплотно / преступно использовать бюджетные средства для личного обогащения. Но даже в случаях типа: Наивно полагать, что $P$ - интерпретатор хотя и не осуждает субъекта, но рассматривает его как интеллектуально менее зрелого, чем он сам (субъект не разобрался в ситуации, в которой интерпретатор разобрался).

Интерпретация оценивает поведение, поступки или выбор человека, за которые тот несет ответственность, т.е., в конечном счете, - оценивает самого человека X, cp. [Kustova 2017]. При этом в случае интерпретации (Неосмотрительно / бессовестно / недостойно и т.д. соглашаться на это) сам X может не знать или не считать, что он поступает неосмотрительно / недостойно и т.д. (см. [Kustova 2004: 219]), - тогда как в случаях типа Если бы вы знали, как тяжело и больно отказывать [Родион Нахапетов. Влюбленный (1998)] X не может не знать, что ему тяжело и больно.

Разницу между внутренней и внешней оценкой можно проиллюстрировать, например, парой страшный - трусливый: страшный описывает эмоцию, которую испытывает субъект Х по поводу какой-то ситуации Р ('Х-у страшно'); трусливый оценивает сам факт реакции Х-а на Р со стороны внешнего наблюдателя, интерпретатора $\mathrm{Y}$-а как тип поведения X-a ('X трусит, боится'). На позицию другого человека или общества может встать и сам субъект, - но модель YX при этом все равно сохраняется, потому что в случае оценки себя со стороны субъект «раздваивается» на «судью» и «подсудимого».

Два основных класса интерпретаций - осуждение (неодобрение) и одобрение.

Диапазон неодобрения весьма широк: авантюрно, безответственно, бессердечно, бессовестно, бесстыдно, бестактно, бесчеловечно, бесчестно, глупо, жестоко, зашкварно (сленг.), наивно, неблагородно, невежливо, неграмотно, недобросовестно, незаконно, неконструктивно, немилосердно, неосмотрительно, неосторожно, неправильно, непредусмотрительно, неразумно, нерационально, несерьезно, нескромно, несправедливо, нечестно, нечистоплотно, неэтично, низко, преступно, самонадеянно, самоуверенно, тщеславно, целесообразно, цинично.

Отрицательных интерпретаций неизмеримо больше, чем положительных (из соображений экономии приводятся минимальные контексты из НКРЯ): Бессовестно выгонять его на улииу; Бестактно допытываться у женщины, сколько она потратила; Бесчестно применять магию в схватке с воинами; Бессердечно разлучать мать с детьми; Безответственно передавать леса в долгосрочную аренду.

Положительные интерпретации тоже встречаются: С его стороны было разумно / предусмотрительно / дальновидно / правильно оставить машину перед офисом; С его стороны было благородно / правильно / справедливо / человечно / этично отказаться от наследства, ср. также: грамотно, остроумно, умно, хитро.

Большинство этих оценок имеют этическое содержание (жестоко vs. благородно); в том числе такие предикативы, как некрасиво (Некрасиво обманывать друзей / Некрасиво грубить старшим = 'не следует, плохо'), которые из эстетической зоны смещаются в этическую. Некоторые оценки не относятся к этической сфере (авантюрно, грамотно, остроумно, умно, хитро). 
Разумеется, приведенный список интерпретаций не исчерпывающий (тем более что он пополняется).

Если в моносубъектных конструкциях субъекты обычно выражаются дативом (Емy страшно подойти к обрыву) или предложной группой для Род. (Очень для меня тяжело переходить из 8ой роты в 4-ую [Александр Гнедин. Письма (1939-1941)], то в интерпретационных конструкциях субъекты X и Y не выражаются обычным способом. Субъект оценки Y (интерпретатор) может быть выражен вводными конструкциями: По-моему / на мой взгляд, неэтично / неправильно / неразумно обсуждать это с коллегами. Указание на субъекта X инфинитивной ситуации V может осуществляться с помощью конструкции с его стороны / со стороны $X-a$ : С его стороны наконеи просто недобросовестно вести неопределенное существование и, таким образом, быть вам в тягость [К. М. Станюкович. Из-за пустяков (1881)]; Со стороны устроителей выставки было в высшей степени бестактно устраивать ее именно в 1937 году [Юрий Елагин. Укрощение искусств (1952)] (в языке XIX-начала XX вв. конструкции с дативом изредка встречались, ср.: Нет, мне просто преступно с вами соглашаться [Н. С. Лесков. Божедомы (1868)], но сейчас их в НКРЯ не обнаруживается).

Не все интерпретационные слова становятся предикативами и употребляются в инфинитивной конструкции ПИнф, но в последние десятилетия эта группа пополняется новыми единицами, хотя интерпретационная конструкция встречалась уже в XIX в. Вот данные из НКРЯ: левая колонка - XIX век + XX век до 1980 г., правая - конец XX (после 1980 г.) - начало XXI вв. (граница, разумеется, условна):

\begin{tabular}{|l|l|l|}
\hline & $\begin{array}{l}\text { До 1980 } \\
\text { (180 лет) }\end{array}$ & $\begin{array}{l}\text { После 1980 } \\
\text { (40 лет) }\end{array}$ \\
\hline Безответственно & \multicolumn{1}{|c|}{-} & 5 \\
\hline Бессердечно & - & 2 \\
\hline Бессовестно & 10 & 6 \\
\hline Бесчеловечно & 14 & 11 \\
\hline Благородно & 7 & 4 \\
\hline Невежливо & 21 & 12 \\
\hline Незаконно & 2 & 6 \\
\hline Неосмотрительно & 1 & 5 \\
\hline Неразумно & 48 & 36 \\
\hline Нескромно & 4 & 6 \\
\hline Несолидно & 1 & 10 \\
\hline Нечестно & 28 & 25 \\
\hline Неэтично & 2 & 6 \\
\hline Преступно & 48 & 18 \\
\hline
\end{tabular}

Заметим, что цифры в колонках неравноценны, поскольку неравноценны временные интервалы. Например, невежливо имеет показатели 21 и 12, но 21 вхождение относится к интервалу в 180 лет, а 12 - к интервалу в 40 лет. Так что даже если в первой колонке число больше, пропорционально оно имеет меньший вес, чем второе число.

У некоторых оценочных предикативов примеры ПИнф пока единичны: Boт и не решались показаться без оружия. Хотя, конечно, грамотнее было бы поскорее избавиться ... [В. Пронин. Слишком большое сходство (2017); Однако же поспешно и необдуманно было бы делать вывод: не найден - не существовал [«Вокруг света», 1994].

Напротив, некоторые единицы закономерно не употребляются в интерпретационной конструкции - например, слова со значением контролируемых усилий: *внимательно было читать / *coсредоточенно было слушать / *настойчиво было просить. Такие единицы не переходят в класс интерпретаций и не функционируют в качестве предикативов (только как наречия или прилагательные: настойчиво просил; настойчивая просьба).

Интерпретационная конструкция существенно отличается от эмоциональной не только по способам выражения субъектов, но и по другим свойствам. Если большинство инфинитивов эмоциональной конструкции - информационные, причем активное и пассивное восприятие (смотреть 
- видеть, слушать - слышать) нейтрализуются, то в интерпретационной конструкции информационные инфинитивы в исходном значении не встречаются, ср. * Несправедливо смотреть / видеть, как гибнут леса. Если же такие глаголы все-таки попадают в интерпретационную конструкцию, с ними происходит семантический сдвиг: Было бы, однако, совершенно несправедливо видеть в Кальвине уже в это время человека с совершенно сложсившимися религиозными убеждениями и вполне выяснившимся враждебным отношением к католицизму [Б. Д. Порозовская. Жан Кальвин (1898)] - видеть ₹ 'усматривать, рассматривать, считать'; Безответственно / бесчеловечно смотреть на все эти безобразия и не вмешаться - 'нельзя мириться с безобразиями'.

Таким образом, ситуации, обозначаемые информационными глаголами, в конструкциях интерпретации приравниваются к поступкам. Причем к поступкам приравниваются не только воззрения, которыми руководствуется человек и за которые он несет ответственность. Как поступок оценивается даже контролируемое восприятие (смотреть, слушать) в собственном смысле, например: Бестактно слушать частные разговоры.

\section{4 Заключение}

Сочетание с инфинитивом наиболее характерно и наиболее естественно для модальных (нужно, необходимо) и близких к ним по значению предикативов (выгодно, полезно $\approx$ 'следует делать'; бесполезно, бессмысленно, вредно, губительно, рискованно $\approx$ 'не следует делать'). Для других предикативов конструкция с инфинитивом является достаточно искусственной. Однако природа этой искусственности разная.

В случае внутренних оценок инфинитивная конструкция чаще всего является результатом «выделения», экстрапозиции информационного предиката (страшно смотреть, горько сознавать). В случае же интерпретационных предикативов за счет инфинитивной конструкции восполняется важная грамматическая лакуна. Для обычного предиката (глагола) основной является предикативная (финитная) форма (сказуемое), но, кроме того, он может иметь адъективную репрезентацию (причастие) и адвербиальную репрезентацию (деепричастие). У интерпретационных смыслов, если они не выражаются глаголом, как бы нет предикативной репрезентации, а есть только адъективная (прилагательное: нерациональный, неосторожный, несправедливый, самонадеянныгй) и адвербиальная (наречие: нераиионально, неосторожно, несправедливо, самонадеянно причем это особые наречия - с так называемой плавающей сферой действия, ср. [Filipenko 1998; 1999; 2003]). Предикатив восполняет грамматическую лакуну - недостаток глагольной репрезентации для интерпретационных смыслов.

Если снабдить интерпретационную лексику семантической разметкой, то различие в конструкциях ПИнф можно использовать в программах автоматической обработки текста для поиска семантической сферы действия предикатива. Разумеется, будут какие-то случаи неразличения, когда предикатив эмоциональной реакции развивает значение интерпретации, ср.:

Странно было читать эту рецензию = внутренняя оценка, реакция: 'странная рецензия, в рецензии было написано что-то странное';

Странно читать такие рецензии = внешняя оценка, интерпретация: 'странно, что X читает такие рецензии', какие именно рецензии - неизвестно; со стороны X-a это странное, неодобряемое поведение.

Однако это касается небольшого количества предикативов типа странно, смешно (и для них можно предусмотреть специальные правила). В остальных случаях автоматический анализ сочетания ПИнф может осуществляться по общему правилу с учетом семантической пометы.

\section{Acknowledgements}

Исследование выполнено при финансовой поддержке РФФИ и Национального научного фонда Болгарии, проект № 20-512-18005.

The reported study was funded by RFBR and National Science Foundation of Bulgaria (NSFB), project number 20-512-18005. 


\section{References}

[1] Apresjan Yu.D. Lexical semantics [Leksicheskaya semantika]. — Moscow: Nauka, 1974.

[2] Apresyan Yu.D. Foundations of systemic lexicography [Osnovaniya sistemnoj leksikografii] // Linguistic picture of the world and systemic lexicography [Yazykovaya kartina mira i sistemnaya leksikografiya]. Ed. by Yu.D. Apresyan. - Moscow: YaSK, 2006a. - P. 33-160.

[3] Apresjan Yu.D. Lexicographic type: verbs of interpretation [Leksikograficheskii tip: glagoly interpretatsii]. // Linguistic picture of the world and systemic lexicography [Yazykovaya kartina mira i sistemnaya leksikografiya]. Ed. by Yu. D. Apresjan. — Moscow: YaSK, 2006b. - P. 145-160.

[4] Boguslavskij I.M. The Scope of lexical units [Sfera dejstvija leksicheskih edinic]. — Moscow: YaSK, 1996.

[5] Filipenko M.V. On adverbials with a floating and fixed scope (to the question of actants and non-actants of a predicate) [Ob adverbialakh s plavayushchei i fiksirovannoi sferoi deistviya (k voprosu ob aktantakh i neaktantakh predikata)] — Semiotics and informatics [Semiotika i informatika]. Issue 36. — Moscow, 1998. - P. 120-139.

[6] Filipenko M.V. Predicative adverbs in -O Predikativnye narechiya na -O // Typology and theory of language. From description to explanation [Tipologiya i teoriya yazyka. Ot opisaniya k ob"yasneniyu]. — Moscow: YaRK, 1999. - P. 503-510.

[7] Filipenko M.V. Semantics of adverbs and adverbial phrases [Semantika narechij i adverbial'nyh vyrazhenij]. - Moscow: Azbukovnik, 2003.

[8] Kustova G.I. The Types of Derived Meanings and Language Extension Mechanisms [Tipy proizvodnykh znachenii i mekhanizmy yazykovogo rasshireniya]. — Moscow: YaSK, 2004.

[9] Kustova G.I. Adjective in the text as a reduced predication [Prilagatel'noe $\mathrm{v}$ tekste kak redutsirovannaya predikatsiya] // Problems of functional grammar. Predicative categories in utterance and whole text [Problemy funktsional'noi grammatiki. Predikativnye kategorii v vyskazyvanii i tselostnom tekste]. - Moscow: YaSK, 2017. - P. 224-246.

[10] Letuchii A.B. Predicatives [Predikativy]. Materials for the corpus grammar of the Russian language [Materialy k korpusnoi grammatike russkogo yazyka]. Issue III. Parts of speech and lexical and grammatical classes [Chasti rechi i leksiko-grammaticheskie klassy]. — Sankt-Peterburg: Nestor-Istoriya, 2018. — P. 136-192.

[11] Paducheva E.V. Dynamic models in lexical semantics [Dinamicheskie modeli v semantike leksiki]. — Moscow: YaSK, 2004.

[12] Serdobol'skaya N.V., Toldova S.Yu. Constructions with evaluative predicatives in Russian: participants in the evaluation situation and the semantics of the evaluative predicate [Konstruktsii s otsenochnymi predikativami v russkom yazyke: uchastniki situatsii otsenki i semantika otsenochnogo predikata]. — Acta Linguistica Petrotolitana. Transactions of the Institute for Linguistic Studies [Trudy Instituta lingvisticheskikh issledovanii]. Vol. X. Part 2. — Sankt-Peterburg: Nauka, 2014. — P. 443-477.

[13] Shcherba L.V. Language system and speech activity [Yazykovaya sistema i rechevaya deyatel'nost']. — Moscow: URSS, 2004 (1-st ed. - 1974).

[14] Sigurdsson H.A. To be an Oblique Subject: Russian vs. Iselandic // Natural Language and Linguistic Theory. -2002. - Vol. 20.

[15] Wierzbicka A. Lexicography and conceptual analysis. — Ann Arbor: Karoma, 1985.

[16] Wierzbicka A. The semantics of grammar. - Amsterdam: Benjamins, 1988.

[17] Zaliznyak Anna A. Polysemy in language and ways of its representation [Mnogoznachnost' v yazyke i sposoby ee predstavleniya]. - Moscow: YaSK, 2006.

[18] Zimmerling A.V. (2017) Russian Predicatives in the Perspective of Sociolinguistic Experiment and Corpus Grammar [Russkie predikativy v zerkale eksperimenta i korpusnoi grammatiki]. // Computational Linguistics and Intellectual Technologies. Papers from the Annual International Conference "Dialogue" (2017) [Komp'yuternaya Lingvistika i Intellektual'nye Tekhnologii: Po materialam Mezhdunarodnoy Konferentsii "Dialog" (2017)],]. Issue 16. Vol. 2. Moscow, pp. 466-481.

[19] Zimmerling A.V. Impersonal constructions and dative-predicative structures in Russian // Voprosy Jazykoznanija. - 2018, No. 5, pp. 7-33. 